\title{
Sequential changes in small intestinal structure and function during rotavirus infection in neonatal rats
}

\author{
A F Salim, A D Phillips, J A Walker-Smith, M J G Farthing
}

\begin{abstract}
Rotavirus infection is the most common cause of acute diarrhoea in children worldwide. The structural and functional consequences of mammalian rotavirus infection in the small intestine have been incompletely studied and the mechanism of enterocyte damage poorly defined. This study used a neonatal rat model of group $B$ rotavirus infection to study the natural history, clinical features, and the structural and functional consequences of infection in the small intestine. Group B rotavirus infection in eight day old neonatal rats produced diarrhoea by 24-36 hours, which was accompanied by weight loss during the early stages of infection. By seven days the diarrhoea had ceased and body weight was similar to noninfected controls. Rotavirus could be recovered in faeces from 24-72 hours. Light microscopy and morphometry confirmed reduction in villous height in both jejunum and ileum, with a reduction in total mucosal thickness indicating true flat mucosa. Increase in crypt depth followed villous shortening and continued as villous height progressively increased between 96-168 hours. Steady state perfusion of the entire small intestine with a plasma electrolyte solution confirmed the presence of a net secretory state for water between 12-48 hours, with a parallel reduction in sodium absorption. Group B rotavirus infection produces a self limiting acute diarrhoeal illness in neonatal rats similar to human rotavirus infection. Infection causes a reversible flat mucosa resulting from enterocyte loss associated with a net secretory state for water and impaired sodium absorption as a functional correlate. These findings may have relevance for the pathogenesis of human rotavirus infection.
\end{abstract}

(Gut 1995; 36: 231-238)

Keywords: Rotavirus infection, small intestine.

Rotavirus is the most common cause of acute gastroenteritis in infants and young children worldwide, ${ }^{1-3}$ yet its pathogenesis remains uncertain. Current evidence suggests that rotavirus diarrhoea is caused by a combination of factors, which include reduction in surface area of the small intestine, replacement of mature villous enterocytes by immature cells, and possibly an osmotic effect resulting from incomplete absorption of carbohydrate in the bowel lumen. ${ }^{4}$ The pathogenesis of flat mucosa is not clearly established but is thought to be the result of direct or indirect enterocyte damage by the virus. For ethical reasons rotavirus diarrhoea is difficult to study in children, although intestinal biopsy studies confirm the occurrence of flat mucosa and virus within enterocytes. ${ }^{5-8}$

Several animal species such as neonatal pigs, lambs, calves, dogs, and rabbits have been used to study small intestinal morphology in rotavirus diarrhoea, ${ }^{9-15}$ however, in these species only a small number, sometimes single animals rather than groups, have been included. The neonatal mouse has been used by several investigators, ${ }^{16-19}$ but villous shortening and crypt hyperplasia are comparatively minor and do not consistently occur, ${ }^{17-19}$ suggesting that this is not a good model of rotavirus infection in children. ${ }^{5-7}$ The pathophysiology of rotavirus diarrhoea, has been studied only in neonatal pigs ${ }^{20-21}$ and mice. ${ }^{22}$ The neonatal pig model has been used for both in vivo ${ }^{21}$ and in vitro ${ }^{20}$ studies. Rotavirus infected neonatal mouse intestine has been studied in vitro using isolated intestinal segments without an intact blood and nerve supply ${ }^{22}$ and thus the pathophysiological relevance of this model might be questioned.

Recently, a group B rotavirus has been reported to cause symptomatic diarrhoea in neonatal rats $^{23}$ and a similar virus can cause diarrhoea in humans. ${ }^{24}$ We have infected neonatal rats with group $B$ rat rotavirus and related the clinical course of diarrhoea to virus excretion in faeces, and to structural and functional abnormalities in the small intestine. This is the first systematic characterisation of this rotavirus infection in neonatal rats, which we consider will prove to be an excellent model for studying pathogenesis of human rotavirus infection.

\section{Methods}

ANIMALS

Neonatal rats (Bantin \& Kingham Ltd, Aldbrough Hill, UK) were obtained at the age of 5 days. For the three days before inoculation, they were kept with their mother and allowed to suckle ad libitum. At the time of inoculation each animal was about $6 \mathrm{~cm}$ long and weighed $12-15 \mathrm{~g}$. At least six to eight animals were studied in each group at each time point. 
VIRUS PREPARATION AND PRODUCTION OF EXPERIMENTAL INFECTION

Group B rotavirus was kindly supplied by Dr S L Vonderfecht, Johns Hopkins University, Baltimore, Maryland, USA. The inocula were prepared by the method of Vonderfecht et al. ${ }^{23}$ Eight day old neonatal rats were intragastrically inoculated with $0.25 \mathrm{ml}$ of material $(0.02 \mathrm{ml}$ of intestinal homogenate containing rotavirus mixed with $0.23 \mathrm{ml}$ water). After inoculation, the rats were returned to their mother and allowed to suckle. After 24 hours, the rats were killed, the whole intestine from duodenum to sigmoid colon removed, pooled, and homogenised in a hand held tissue grinder for 20 minutes. The homogenate was added to RPMI-1640 culture medium (Gibco Ltd, Scotland) to produce a $10 \%$ weight by volume suspension and centrifuged at $13000 \times g$ for five minutes in a MSE Superspeed 50 centrifuge. The supernatant was filtered through a $0.22 \mu \mathrm{m}$ pore size membrane and the filtrate stored in $500 \mu \mathrm{l}$ aliquots at $-30^{\circ} \mathrm{C}$. When required the filtrate was thawed and mixed with $5.75 \mathrm{ml}$ water to produce $6.25 \mathrm{ml}$ of material, which was sufficient to infect 25 animals.

Rats were weighed before inoculation and daily thereafter to an accuracy of $0 \cdot 1 \mathrm{~g}$. To detect the presence of diarrhoea, rats were held by their dorsal surface and the anal region carefully examined. If no faeces were present, the abdomen was gently massaged to promote passage of faeces, which always occurred immediately in diarrhoeic rats. Time of appearance of first loose stool was taken as the onset of diarrhoea. Rats were examined at six hour intervals for the first 24 hours, at 12 hourly intervals for 48 hours, and then daily. Non-infected control rats were gavaged with $0.2 \mathrm{ml}$ water but were otherwise treated identically to rotavirus infected rats.

\section{HISTOLOGY AND MORPHOMETRY}

Approximately $1 \mathrm{~cm}$ sections of intestine were taken at $10 \mathrm{~cm}$ distal to duodenjejunal flexure and $10 \mathrm{~cm}$ proximal to ileocaecal junction, opened along the mesenteric border, and orientated villous surface up on a piece of black card. Tissue sections were fixed in $10 \%$ phosphate buffered formal saline at room temperature.

\section{Light microscopy}

Haematoxylin and eosin and periodic acid schiff (PAS) stained specimens from control and infected rats at 12-168 hours were examined with an Olympus BHB light microscope. At least six well orientated villi and their adjacent crypts were examined in each specimen.

\section{Electron microscopy}

Stool specimens were negatively stained $(2 \cdot 5 \%$ phosphotungstic acid, pH 6.6) and examined at different times after infection for the detection of rotavirus using a Philips 300 electron microscope. A minimum of five grid squares were examined and samples were considered negative if no virus particles were detected within 10 minutes observation; the presence of rotavirus was semiquantified as,+++ , or +++ , when an average of less than $5,5-15$, or greater than 15 particles per grid square were seen, respectively.

To detect rotavirus in epithelial cells, tissues were collected from the jejunum and ileum of infected rats at $12,18,24,30$, and 48 hours and fixed in $3 \%$ glutaraldehyde in $0.1 \mathrm{~m}$ phosphate buffered saline (PBS), $\mathrm{pH} 7 \cdot 3$ at $4^{\circ} \mathrm{C}$. Tissues were postfixed in $1 \%$ osmium tetroxide, dehydrated in 2,2 dimethoxypropane, and embedded in TAAB resin (TAAB Lab, UK). Sections of $100 \mathrm{~nm}$ thickness were stained with uranyl acetate and lead citrate and examined in a Phillips 300 electron microscope.

\section{Morphometry}

Whole sections of tissues were assessed morphometrically using the methods of Maluenda et al. ${ }^{25}$ Haematoxylin and eosin and PAS stained sections were examined at a total magnification of 116 times using a drawing arm attachment on an Olympus BMB light microscope. Only well orientated sections were studied and care was taken to ensure that only longitudinal sections cut perpendicularly to the muscularis mucosae were included.

During the examination the villus tip, the villus-crypt junction, and the length of the crypt zone were marked. Where the base of the crypt zone could not be identified clearly, the junction of the crypt with the muscularis mucosae was taken as the base. At least 10 villous height and crypt depth measurements were made on each specimens. ${ }^{26}$

A Tektronix 4052 microcomputer and a digitising tablet with a 'follower' was used to take the measurements of the parameters under study. The 'follower' contains a fine cross hair set in it for precise placement on the tracing and it was run over the aspect of the markings to be measured. The position of the follower on the digitising tablet can be accurately registered by the computer within $0.1 \mathrm{~mm}$. With suitable programming it permits the measurement of straight lines. The accuracy of the measurements was assessed by repeating them five times and calculating the mean results. The difference between the most divergent results was expressed as a percentage of the mean for the measurements. All the measurements were within $0.7 \%$ of the mean, and thus confirming the accuracy of the method.

PERFUSION OF THE ENTIRE SMALL INTESTINE Steady state perfusion of the entire small intestine of neonatal rats was performed as we have described previously. ${ }^{27}$ Rats were anaesthetised with intraperitoneal sodium pentobarbital (Sagatal, May \& Baker Ltd, UK). For initial anaesthesia $4.8 \mathrm{mg} / \mathrm{kg}$ body weight was used, while for maintenance $1.2 \mathrm{mg} / \mathrm{kg}$ was 


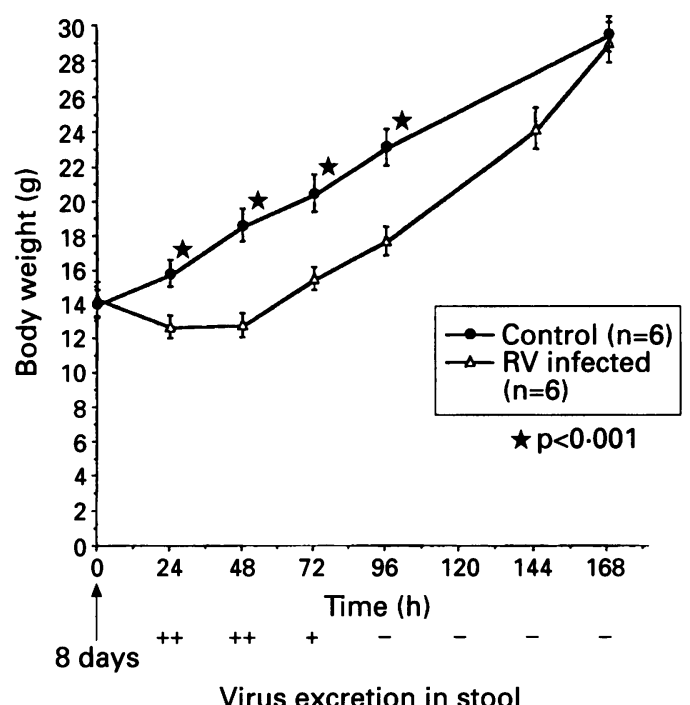

Figure 1: Body weight (mean (SEM)) in control and rotavirus (RV) infected neonatal rats. Excretion of rotavirus in faeces during the course of infection is shown semiquantitatively along the horizontal axis $(+,++$, and +++ ).

given intramuscularly as necessary. After anaesthesia, laparotomy was performed by a midline incision and proximal duodenum and distal ileum just adjacent to caecum were ligated. A polyethylene cannula (internal diameter $0.76 \mathrm{~mm}$ ) was then inserted into the second part of duodenum and advanced to duodenojejunal flexure. This cannula was used to deliver the test solution. A second polyethylene tube (internal diameter $1.4 \mathrm{~mm}$ ) was inserted into the most distal part of the ileum to serve as the collecting tube. Care was taken to avoid damage to the blood vessels supplying the section of the small intestine to be perfused and the abdomen was then closed. Body temperature was maintained at $37 \pm 0.5^{\circ} \mathrm{C}$ using a heating pad and by monitoring rectal temperature.

Before the perfusion, the entire small intestine was gently lavaged with isotonic sodium chloride at $37^{\circ} \mathrm{C}$. A plasma electrolyte solution (Na 140, K 4, $\mathrm{HCO}_{3}$ 30, Cl 104 mM; osmolality $297 \pm 0.3 \mathrm{mOsm} / \mathrm{kg}$ ) containing a nonabsorbable marker $\left[{ }^{14} \mathrm{C}\right]$-polyethylene glycol (PEG) $4 \mu \mathrm{Ci} / 1$ was then perfused from a $50 \mathrm{ml}$ infusion syringe using a Braun ED2 pump (Braun Ltd, Germany) at a rate of 0.25 $\mathrm{ml} / \mathrm{min}$. Ten $\mathrm{ml}$ plasma electrolyte solution was perfused through the intestine, after which

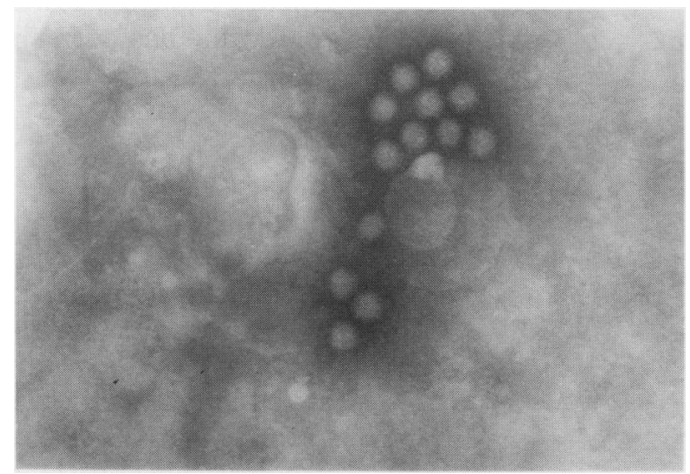

Figure 2: Electron micrograph of negatively stained faecal specimen showing typical $67 \mathrm{~nm}$ diameter rotavirus particles. a 30 minute equilibration period was allowed to achieve a steady state. After this three successive 10 minute collections were made from the distal cannula for analysis. The establishment of a steady state was confirmed by ensuring that the concentration of PEG in each of three successive collections varied $<10 \%$ about the mean. ${ }^{28}$ The recovery of PEG in these experiments was $97 \cdot 0(0 \cdot 4) \%$ (mean (SD)).

At the end of experiment, the rats were killed and the perfused segment of the small intestine gently removed and dried in a hot air oven at $100^{\circ} \mathrm{C}$ for 18 hours and weighed.

\section{STATISTICAL METHODS}

Student's $t$ test was used to assess the statistical significance of differences in weight gain between control and infected rats. A non-parametric two tailed Mann-Whitney $U$ test was used for other comparisons for which a commercially available statgraphics package ${ }^{29}$ was run on a personal IBM computer.

\section{Results}

DURATION OF DIARRHOEA

Diarrhoea was seen in some animals at 24 hours but by 36 hours all infected rats had diarrhoea. In addition, they appeared anorexic, dehydrated, and developed reddening and subsequently cracking of the perianal skin. Diarrhoea persisted for five to six days. None of the infected rats died. Control rats did not develop diarrhoea.

\section{BODY WEIGHT}

At 24 hours body weight of infected rats was significantly lower than age matched controls (Fig 1). Mean body weight of rotavirus infected rats at 24 hours was also significantly lower than their own pre-inoculation weight indicating weight loss during the infection. From 24-48 hours there was no further loss of weight, but at 48 hours mean weight was still significantly lower than pre-inoculation weight while the control rats continued to grow. At 72 hours significant weight gain was seen in the infected rats, although this was less than controls. From 96 hours onward, 'catch-up' weight gain occurred such that at 168 hours there was no difference in body weights between the control and infected rats.

\section{EXCRETION OF ROTAVIRUS}

Rotavirus was detected in the intestinal washings of infected rats first at 18 hours and in the faeces from 24-72 hours (Fig 1). From 96-144 hours, when diarrhoea was improving but not completely resolved, rotavirus was not detected.

\section{Electron microscopy of tissue sections}

In the tissue sections, rotavirus was detected in aggregate form in the cytoplasm of syncytial 


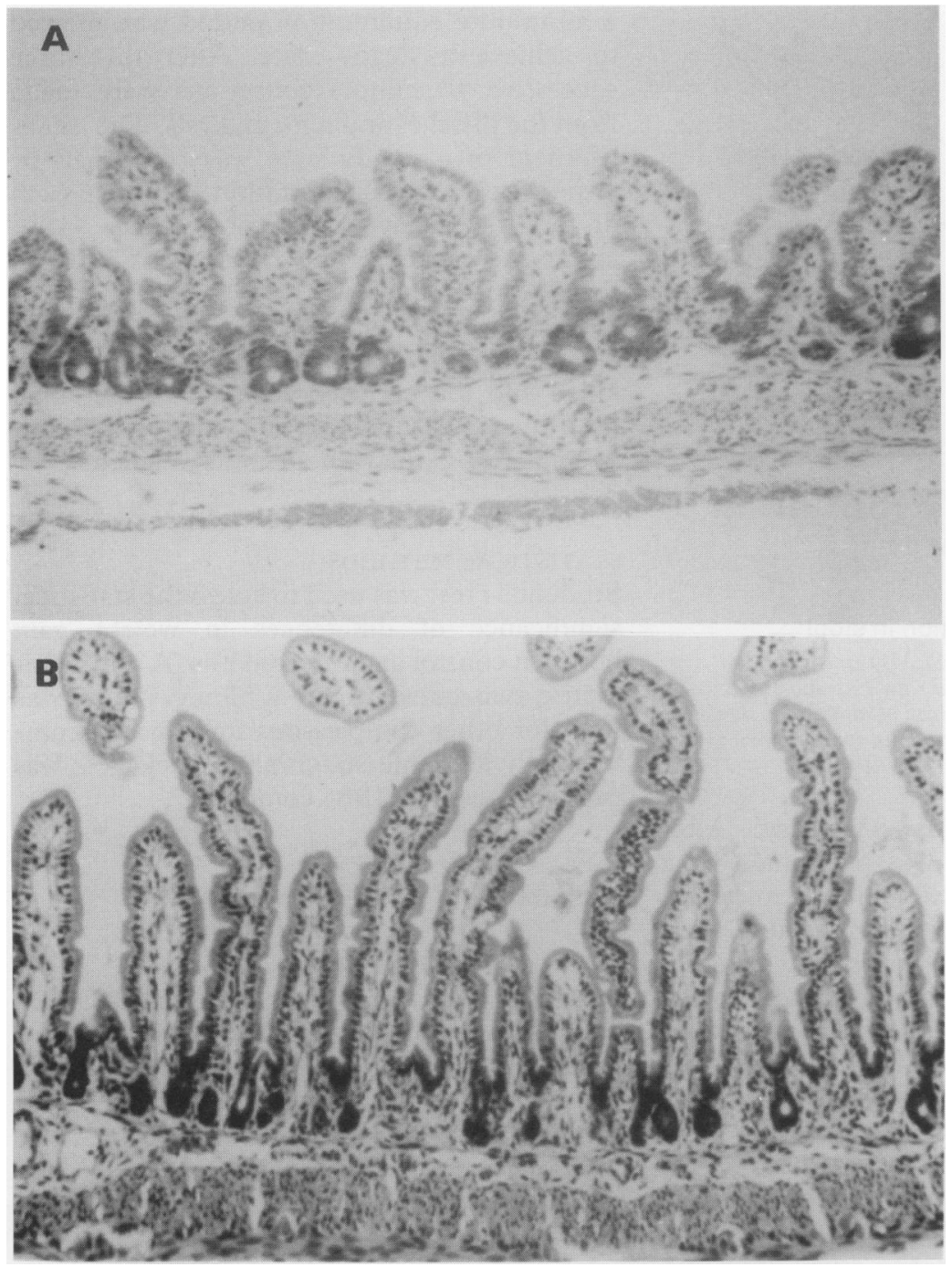

Figure 3: Rotavirus infected $(A)$ and control $(B)$ rat jejunum 24 hours after gavage of rat group $B$ rotavirus particles. cells (see later) at 24 hours. Individual viral particles were circular about $67 \mathrm{~nm}$ in diameter (Fig 2).

\section{HISTOLOGY AND MORPHOMETRY}

Light microscopy of haematoxylin and eosin and PAS stained sections of the jejunum and ileum from the control rats at 0,72 , and 168 hours showed tall finger like villi, thin crypts with tall columnar epithelial cells having basally placed nuclei, and a large supranuclear area occupying almost the whole apical cytoplasm. PAS positive material, thought to be maternal IgG was found in ileal epithelial cells at 0 and 72 hours (data not shown).

Villi were shortened in infected rats, first apparent at 12 hours in the ileum and 18 hours in the jejunum and remained abnormal for up to 72 hours in the jejunum and 96 hours in the ileum. Most severe shortening was seen at 24 hours (Fig 3 ), with cuboidal cells lining the villi instead of columnar epithelial cells. These changes gradually returned to normal by 96 hours. Syncytial cell formation was noted in the villus at 18 hours in the jejunum (Fig 4) and at 24 hours in the ileum. Syncytial contained clearer cytoplasm and multiple nuclei. Syncytial cells were found throughout the villus, but never in the crypts. The crypts were elongated at 48 hours in both jejunum and ileum with increased number of mitotic figures at 72 hours. The crypts remained elongated at 168 hours, which was the end of study period. A few vacuolations at the tip of the villi were noted at 12 and 48 hours in the jeunum and at 48 hours in the ileum. The PAS positive material (possibly maternal IgG) could be seen in the ileal epithelial cells only up to 18 hours but never later (data not shown). The number of cells in the lamina propria did not increase at any time and the intraepithelial lymphocyte count remained within normal limits. Brush border was intact throughout the study period.

Morphometric results are plotted as multiple box and whisker plots and show median, upper and lower quartiles, and maximum and minimum values (Figs $5-8) .{ }^{29}$ When any single value was extremely high or low and the difference between the quartile and the extreme value was more than 1.5 times the interquartile range, the value was individually plotted in the Figure. The 1.5 times value was either added to the upper quartile value or subtracted from the lower quartile value and this final value has been shown as the maximum or minimum value.

\section{Villous height}

Villous height in control rats increased significantly from 0 to 168 hours in both jejunum and ileum (Fig 5A and B). In infected rats there was a significant reduction in villous height compared with controls in the jejunum at 18 hours, which persisted at $24,48,72$ hours (Fig 5A). At 96-168 hours villous height progressively returned to normal such that there was no significant difference between control and infected rats by the end of the 

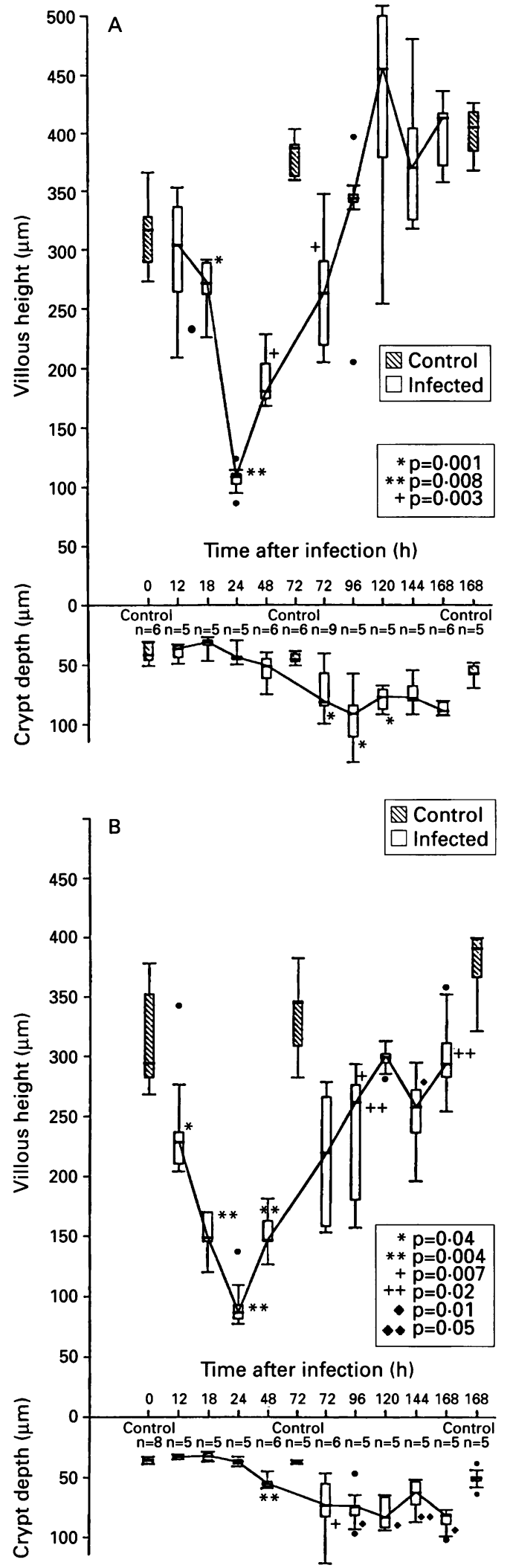

Figure 5: Villous height and crypt depth (median, upper, and lower quartiles and maximum and minimum values) in jejunum $(A)$ and ileum $(B)$ in controls $(0,72$, and 168 hours) and in rotavirus infected neonatal rats (12-168 hours).

study period at 168 hours. In the ileum, significant reduction in villous height first occurred at 12 hours and was maintained at 18, 24, 48, 72, and 96 hours (Fig 5B). At 120 hours villous height had increased such that there was no significant difference in villous height between controls at $0-168$ hours.
Crypt depth

Crypt depth in control jejunum and ileum was similar at 0 and 72 hours, but was significantly increased at 168 hours (Fig 5A and B). In the jejunum of the infected rats, a significant increase in crypt depth was first noted at 72 hours, which persisted until 120 hours. At 144 and 168 hours values were similar to controls at 168 hours. In the ileum, crypt depth was increased first at 48 hours and remained increased throughout the study period.

\section{Total mucosal thickness}

Mucosal thickness in the jejunum and ileum of controls increased from 0 to 168 hours (Fig 6A and $B$ ). In infected rats total mucosal thickness in the jejunum was decreased by 18 hours and remained so at 24,48 , and 72 hours. In the ileum reduction in total mucosal thickness was first seen at 12 hours and this continued until 48 hours. Total mucosal thickness was still reduced at 168 hours compared with controls.

Villous height/crypt depth ratio (VH/CD)

$\mathrm{VH} / \mathrm{CD}$ ratio in controls was unchanged in the
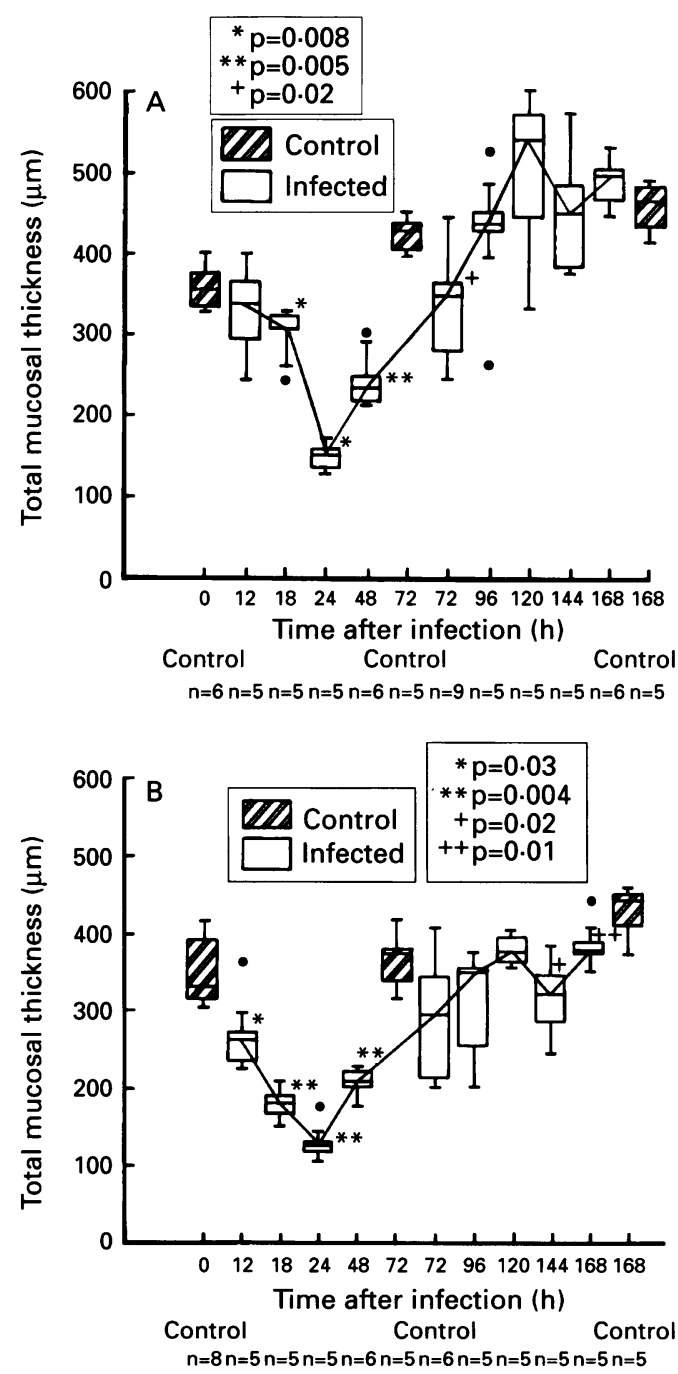

Figure 6: Total mucosal thickness (median, upper, and lower quartiles and maximum and minimum values) in jejunum $(A)$ and ileum $(B)$ in controls $(0,72$, and 168 hours) and in rotavirus infected neonatal rats (12-168 hours). 

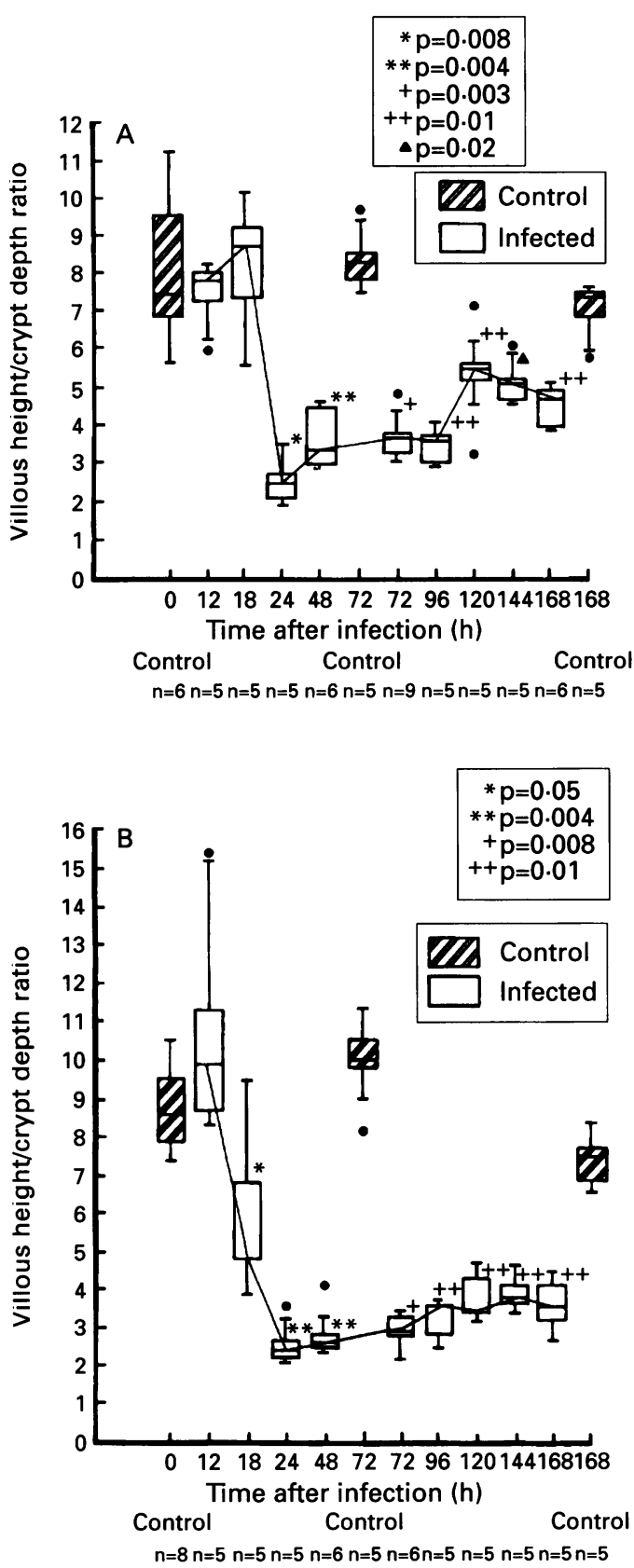

Figure 7: Villous height/crypt depth ratio (median, upper and lower quartiles, and maximum and minimum values) in jejunum $(A)$ and ileum $(B)$ in controls $(0,72$, and 168 hours) and in rotavirus infected neonatal rats (12-168 hours).

jejunum and ileum at 72 hours and 168 hours. In infected rats, VH/CD ratio was decreased in the jejunum and ileum at 24 hours and remained low until 168 hours (Fig 7A and B).

\section{WATER AND ELECTROLYTE TRANSPORT}

\section{Net water movement}

In controls at 0 and 96 hours there was net absorption of water from plasma electrolyte solution. In infected rats there was significant reduction in net water absorption at 12 hours and by 18 hours a net secretory state for water existed, which continued up to 48 hours. At 72 and 96 hours net water secretion reverted to absorption although still significantly less than controls (Fig 8A).
Net sodium movement

Net absorption of sodium from plasma electrolyte solution in controls occurred at 0 and 96 hours. In infected rats net sodium paralleled water movement with reduction in net sodium absorption occurring at 24 hours postinfection (Fig 8B).

\section{Discussion}

In this study we have characterised the natural history and structural and functional disturbances in the small intestine of experimental group B rotavirus infection in the neonatal rat. Rotavirus induced an acute enteric disease in 8 day old neonatal rats consisting of diarrhoea, dehydration, anorexia, and weight loss. Infection was self limiting, non-fatal, and did not cause any longterm effects on growth and development. These findings are similar to those in natural human rotavirus infection ${ }^{30-34}$ and in some other animal species. ${ }^{9} 121735$

In this study weight loss occurred at the onset of diarrhoea, and was associated with erythema, cracking, and sometimes bleeding of the perianal skin. Similar findings were reported in a different strain of rat by Vonderfecht et $a l^{23}$ and other species ${ }^{103435}$ although these are not consistent findings in all animals ${ }^{36-38}$ and do not usually occur in human infection. ${ }^{39}$ Weight loss in infected rats was rapidly reversed, as reported by others. ${ }^{10} 34$ Heyman et al ${ }^{35}$ working with rotavirus infection of both conventional and germ free seronegative mice found that the mice did not regain the lost weight even after nine days postinfection.

Villous epithelial syncytial cell formation only occurred between 18 and 24 hours in this study. Syncytial cells have been reported by others, ${ }^{23} 36$ but Thiel et al ${ }^{38}$ working with a group B rotavirus in neonatal gnotobiotic pigs found no evidence of syncytial cells although only a comparatively small number of animals were studied. The discrepancy between these findings may be related to technical factors. Syncytial cells usually shed off very rapidly after formation and if the specimen is not collected at an appropriate time, these cells may not be seen. We found large numbers of viral particles in aggregate form in the cytoplasm of syncytial cells but never in other cells. In contrast with human group $B$ rotavirus infections, ${ }^{39}$ no budding of the viral particles into vesicles of rough endoplasmic reticulum was seen ${ }^{40}$ nor were there tubular structures in the cytoplasm. ${ }^{17}$

Flat mucosa was a constant lesion found in the infected rats and was most severe at the onset of diarrhoea. As the villous height gradually returned to normal, there was a corresponding reduction in the severity of clinical signs and infected rats began to gain weight. Thus, recovery from rotavirus infection occurred in parallel with regeneration of damaged villi and probable resumption of normal digestive-absorptive function. These findings are in agreement with other studies. ${ }^{19} 34$ Flat mucosa has been reported in other animal species, ${ }^{9121423}$ and in 

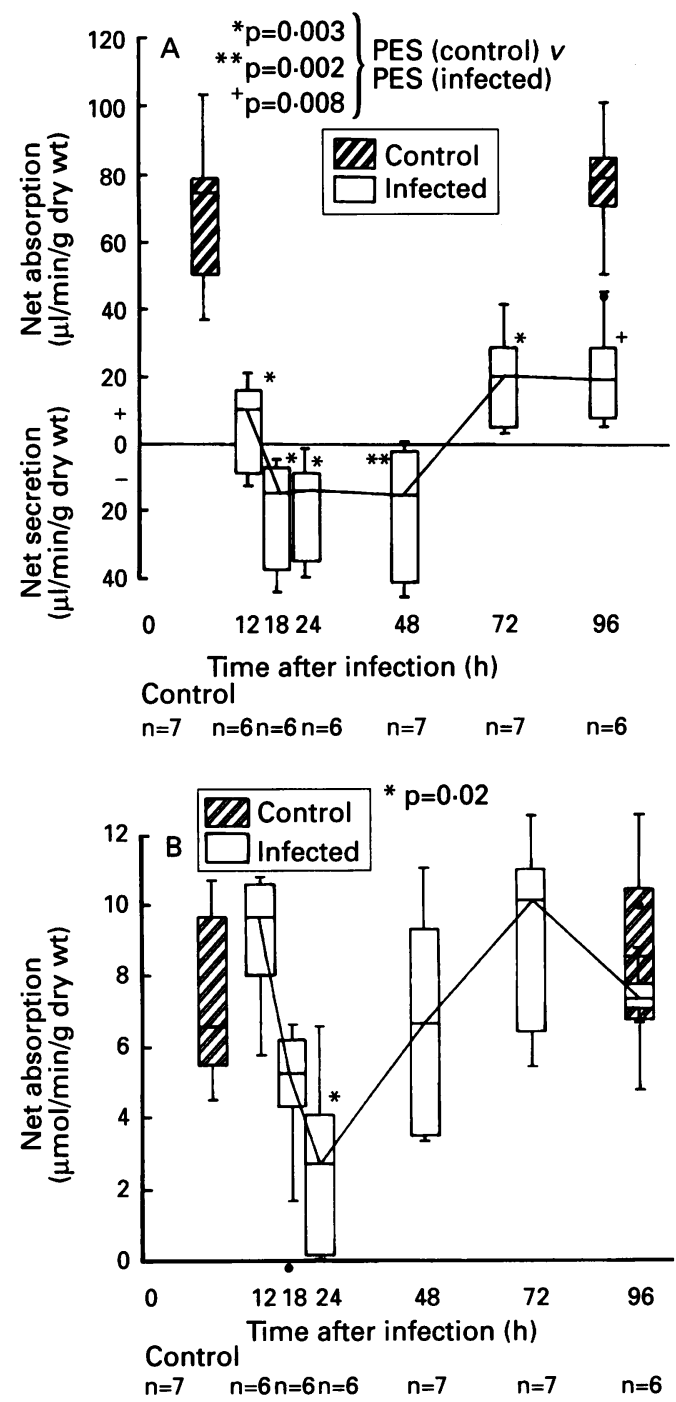

Figure 8: Net water $(A)$ and sodium (B) movement from plasma electrolyte solution (PES) in rotavirus infected (12-96 hours) and non-infected control ( 0 and 96 hours) neonatal rat jejunum. Data are plotted as median, upper and lower quartiles, and maximum and minimum values.

humans. ${ }^{67}$ In contrast with these findings, flat mucosa was not found in EDIM virus infection of neonatal mice. ${ }^{17-19}$ Extensive intra and intercellular vacuolation of the villus tip enterocytes has been found to be a constant feature in mice, ${ }^{18}$ which was only occasionally seen in these studies. It is therefore probable that the pathology of EDIM virus infection in mice differs from rotavirus infection in most other mammals. Morphometry confirmed significant reduction in villous height in the ileum at 12 hours and the jejunum at 18 hours. At this stage the rats, however, did not have clinical diarrhoea and it is probable that the colon, which is usually not involved in rotavirus infection, could cope with the amount of fluid presented to it and effect adequate water and sodium retrieval. At 24 hours, however, when the flat mucosa was most severe, the amount of fluid presented to the colon could not be absorbed with the occurrence of clinical diarrhoea. ${ }^{4142}$

Crypt hypertrophy was first noted in the ileum at 48 hours and in the jejunum at 72 hours, whereas net secretion of water occurred between 18-48 hours but reverted to a net absorptive state by 72 hours. These findings argue against the concept that diarrhoea is caused by the presence of immature crypt like cells with reduced digestive/absorptive capacity, which repopulate the villi after rotavirus damage. ${ }^{2021}$ Thus the onset of diarrhoea coincides with flat mucosa and precedes the appearance of crypt hyperplasia.

When the whole small intestine was perfused with glucose free plasma electrolyte solution net secretion of water was seen from 18-48 hours, while there was net absorption at 12,72 , and 96 hours, although significantly less than in controls. At 24 hours, when flat mucosa was most profound, net absorption of sodium was significantly reduced. At this time, villi were populated with cuboidal cells in place of normal columnar epithelial cells, consistent with our findings that the absorptive capacity of the epithelium was reduced. Lining of the epithelium by cuboidal cells at the peak of rotavirus diarrhoea has been seen by others ${ }^{101113}$ and net secretion of water has been described in in vivo ${ }^{21}$ and in vitro 2022 studies. During this early period, no change in crypt depth was seen although when regeneration started the cuboidal cells lining the epithelium were gradually replaced by normal columnar cells and regeneration of villi paralleled clinical recovery. Net absorption of sodium occurred in infected animals throughout the study period. A linear correlation between concentration of sodium in the perfusion solution and the rate of sodium absorption in the intestine has been reported by several workers. ${ }^{43-45}$ The concentration of sodium in the solution perfused was comparatively high $(140 \mathrm{mmol} / \mathrm{l})$, which may explain why sodium absorption persisted in the infected rats despite net water secretion at 18-48 hours. At 24 hours when reduction in villous height was most pronounced, net sodium absorption was maximally reduced. These data suggest that destruction of villous epithelial cells was the important determinant of impaired sodium transport by the intestinal mucosa.

Therefore, from these and other studies 91112 it seems that group B rotavirus causes a rapid and extensive infection of mature, differentiated enterocytes in the neonatal rat. This infection leads to formation of syncytial cells and loss of epithelial cells into the lumen. This results in impairment of water and sodium absorption. Clinical recovery coincided with improvement of villous height towards normal values and the disappearance of rotavirus from the stools.

Dr A F M Salim was a Commonwealth University Fellow and gratefully acknowledges financial support. Professor M J G Farthing gratefully acknowledges financial support of the Wellcome Trust. We express our gratitude to the Histopathology Department, Hospital for Sick Children, Great Ormond Street for processing material for histological examination.

1 Kapikian AZ, Kim HW, Wyatt RG, Chine WL, Arrobio JO, Breandt $C D$, et al. Human reovirus-like agent as the major pathogen associated with 'winter' gastroenteritis in pathogen associated with 'winter' gastroenteritis in 1976; 294: 965-72.

2 Black RE, Merson MH, Rahman ASMM, Yunus M, Alim ARMA, Huq I, et al. A two year study of bacterial, viral ARMA, Huq I, et al. A two year study of bacterial, viral and parasitic agents associated with diarr 
3 Walker-Smith JA. Diseases of the small intestine in child hood. 3rd ed. London: Butterworths, 224-37.

4 Mathan MM. The small intestine: specific infection and tropical sprue. In: Whitehead R, ed. Gastrointestinal and oesophageal pathology. Edinburgh: Churchill Livingstone, 1989: 443-57.

5 Bishop RF, Davidson GP, Holmes IH, Ruck BJ. Virus particles in epithelial cells of duodenal mucosa from children with acute non-bacterial gastroenteritis. Lancet 1973; ii: 1281-3.

6 Suzuki H, Konno T. Reovirus-like particles in jejunal mucosa of a Japanese infant with acute infectious non bacterial gastroenteritis. Tohoku f Exp Med 1975; 115: 199-211.

7 Davidson GP, Barnes GL. Structural and functional abnormalities of the small intestine in infants and young
children with rotavirus enteritis. Acta Paediatr Scand children with rotavi

8 Phillips AD. Small intestinal mucosa in childhood in health and disease. Scand $\mathcal{f}$ Gastroenterol 1981; suppl 70: 65-85.

9 Theil KW, Bohl EH, Cross RF, Kholer EM, Agnes AG Pathogenesis of porcine rotaviral infection in experimentally inoculated gnotobiotic pigs. Am $\mathcal{f}$ Vet Res 1978 39: 213-20.

10 Crouch CF, Woode GN. Serial studies of virus multiplication and intestinal damage in gnotobiotic piglets infected with rotavirus. 7 Med Microbiol 1978; 11: 325-34.

11 McAdaragh JP, Bergeland ME, Meyer RC, Johnshoy MW, Stotz IZ, Benfield DA, et al. Pathogenesis of rotaviral enteritis in gnotobiotic pigs: a microscopic study. enteritis in gnotobiotic pigs:

12 Snodgrass DR, Angus KW, Gray EW. Rotavirus infection in lambs: pathogenesis and pathology. Arch Virol 1977; 55: 263-74.

13 Mebus CA, Newman LE. Scanning electron, light and immunofluorescent microscopy of intestine of gnotobiotic calf infected with reovirus-like agent. Am $\mathcal{F}$ Vet Res 1977 38: 553-8.

14 Johnson CA, Snider TG, Henk WG, Fulton RW. A scanning and transmission electron microscopic study of rotavirus-induced intestinal lesions in neonatal gnotobiotic dogs. Vet Pathol 1986; 23: 443-53.

15 Conner ME, Estes MK, Graham DY. Rabbit model of rotavirus infection. 7 Virol 1988; 62: 1625-33.

16 Adams WR, Kraft LM. Electron microscopic study of the intestinal epithelium of mice infected with the agent epizootic diarrhoea of infant mice (EDIM) virus. epizootic diarrhoea of inf

17 Coehlo KIR, Bryden AS, Hall C, Flewett TH. Pathology of rotavirus infection in suckling mice: a study by conventional histology, immunofluorescence, ultrathin section and scanning electron microscopy. Ultrastruct Pathol 1981; 2: 59-80.

18 Starkey WG, Collins J, Wallis TS, Clark GJ, Spencer AJ, Haddon SJ, et al. Kinetics, tissue specificity and pathological changes in murine rotavirus infection of mice. $\exists$ Gen Virol 1986; 67: 2625-34.

19 Osbourne MP, Haddon SJ, Spencer AJ, Collins J, Starkey WG, Wallis TS, et al. An electron microscopic investigation of the related changes in the intestine of neonatal tion of the related changes in the intestine of neonatal mutr 1988; 7: 236-48.

20 Davidson GP, Gall DG, Petric M, Butler DG, Hamilton JR Human rotavirus enteritis induced in conventional piglets: intestinal structure and transport. $\mathcal{F}$ Clin Invest 1977; 60 1402-9.

21 Graham DY, Sackman JW, Estes MK. Pathogenesis of rotavirus induced diarrhoea: preliminary studies in miniature swine piglets. Dig Dis Sci 1984; 29: 1029-35.

22 Starkey WG, Candy DCA, Thronber D, Collins J, Spencer AJ, Osborne MP, et al. An in vitro model to study aspects of the pathophysiology of murine rotavirus-induced of the pathophysiology of murine rotavirus-induced
diarrhoea. $\mathcal{F}$ Pediatr Gastroenterol Nutr 1990; 10: 361-70.

23 Vonderfecht SL, Huber AC, Eiden JJ, Mader LC, Yolken $\mathrm{RH}$. Infectious diarrhoea of infant rats produced by rotavirus-like agent. $\mathcal{f}$ Virol 1984; 52: 94-8.
24 Eiden JJ, Vonderfecht SL, Yolken RH. Evidence that a novel rotavirus-like agent of rats can cause gastroenteritis novel rotavirus-like agent of rats
in man. Lancet 1985; ii: 8-11.

25 Maluenda C, Phillips AD, Bridden A, Walker-Smith JA Quantitative analysis of small intestinal mucosa in cow's milk sensitive enteropathy. $\mathcal{F}$ Pediatr Gastroenterol Nutr 1984; 3: 349-56.

26 Snodgrass DR, Ferguson A, Allan F, Angus KW, Mitchel B. Small intestinal morphology and epithelial cell kinetics in lamb rotavirus infection. Gastroenterology 1979; 76 477-81.

27 Hunt JB, Salim AFM, Thillainayagam AV, Carnaby S, Elliott EJ, Farthing MJG. Water and solute absorption from a new hypotonic oral rehydration solution: evaluation in animal and human perfusion models. Gut 1992; 33: 1652-9.

28 Elliott EJ, Watson AJM, Walker-Smith JA, Farthing MJG Effect of bicarbonate on efficacy of oral rehydration therapy: studies in an experimental model of secretory diarrhoea. Gut 1988; 29: 1052-7.

29 Brown RA, Swanson-Beck J. Statistics on microcomputers. A non-algebraic guide to their appropriate use in biomedical research and pathology practice. 3. Analysis of variance and distribution-free methods. $\mathcal{f}$ Clin Pathol 1988; 41: 1256-62.

30 Shepherd RW, Truslow S, Walker-Smith JA, Bird R, Cutting W, Darwell R, et al. Infantile gastroenteritis - A clinical study of reovirus-like agent infection. Lancet 1975 ; ii: $1082-4$.

31 Tallet S, MacKenzie C, Middleton P, Kerzner B, Hamilton R. Clinical, laboratory and epidemiologic features of a $\mathrm{R}$. Clinical, laboratory and epidemiologic features of a viral gastroenteritis

$32 \mathrm{Maki} M$. A prospective study of rotavirus diarrhoea in young children. Acta Paediatr Scand 1981; 70: 107-13.

33 Hjelt K, Krasilnikoff PA, Grauballe PC, Rasmussen SW. Clinical features in hospitalised children with acute gastroenteritis. Acta Paediatr Scand 1985; 74: 96-101.

34 Kovacs A, Chan L, Hotrakitya C, Olvertwif G, Portnoy B. Rotavirus gastroenteritis. Clinical and laboratory features and use of the rotazyme test. Am 7 Dis Child 1987; 141: 161-6.

35 Gouvea VS, Alencar AA, Barth OM, De Castro L, Fialho AM, Araujo HP, et al. Diarrhoea in mice infected with human rotavirus. $\mathcal{F}$ Gen Virol $1986 ; 67: 577-81$.

36 Heyman M, Corthier G, Petit A, Meslin J-C, Moreau C, Desjeu J-F. Intestinal absorption of macromolecules during viral enteritis: an experimental study on rotavirus infected conventional and germ-free mice. Pediatr Res 1987; 22: 72-8.

37 Askaa J, Bloch B. Infection in piglets with a porcine rotavirus-like virus. Experimental inoculation and ultrastructural examination. Arch Virol 1984; 80: 291-303.

38 Theil KW, Saif LJ, Moorehead PD, Whitmoyer RE. Porcine rotavirus-like virus (Group B rotavirus): characterization and pathogenicity for gnotobiotic pigs. 7 Clin Microbiol 1985; 21: 340-5.

39 Hung T, Chen GM, Wang C, Yao H, Fang Z, Chao T, et al. Waterbourne outbreak of rotavirus diarrhoea in adults in China caused by a novel rotavirus. Lancet 1984; i: 1139-42:

40 Saif LJ, Theil KW, Bohl EH. Morphogenesis of porcine rotavirus in porcine kidney cell cultures and intestinal
epithelial cells. $\mathcal{F}$ Gen Virol $1978 ; 39: 205-17$.

41 Read NW. Diarrhoea: the failure of colonic salvage. Lance 1982; ii: 481-3.

42 Murphy AM, Albrey MB, Crewe EB. Rotavirus infection in neonates. Lancet 1977; ii: $1149-50$.

43 Curran PF, Soloman AK. Ion and water fluxes in the ileum of rats. F Gen Physiol 1960; 41: 143-68.

44 Jones BJM, Higgins BE, Silk DBA. Jejunal $\mathrm{Na}^{+}$absorption is concentration dependent. Gut 1984; 235: A1 163.

45 Kerzner B, Kelly MH, Gall DG, Butler DG, Hamilton JR. Transmissible gastroenteritis: sodium transport and the intestinal epithelium during the course of viral enteritis. Gastroenterology 1977; 72: 457-61. 